\title{
REDUCTION IN THE RISE OF SYSTOLIC BLOOD PRESSURE DURING HUMAN COITUS BY THE $\beta$-ADRENERGIC BLOCKING AGENT, PROPRANOLOL
}

\author{
G. A. FOX* \\ 176 Charlton Road, London, S.E.7
}

(Received 2nd March 1970)

\begin{abstract}
Summary. The ingestion of 120 to $160 \mathrm{mg}$ of the $\beta$-adrenergic blocking agent, propranolol, caused a significant reduction in the rise of systolic blood pressure which occurs during human coitus. The accompanying tachycardia was also reduced. If used with caution and with careful selection of patients, the $\beta$-adrenergic blocking drugs may allow patients with ischaemic heart disease or hypertension a safer and more normal marital life, since the ease of attainment and the intensity of orgasm was not impaired.
\end{abstract}

It has been shown previously (Fox \& Fox, 1969) that there is a rise of systolic blood pressure during coitus, with a peak occurring at orgasm. Since it might be of value to reduce this rise in patients who are hypertensive or who have ischaemic heart disease, the present study was undertaken.

Using a Winston Blood Pressure Follower, which employs a digital cuff and gives a continuous record of the systolic blood pressure, experiments were conducted on the couple previously described by Fox \& Fox (1969). A test dose of $10 \mathrm{mg}$ of propranolol was taken orally as a precautionary measure to avoid the precipitate fall in pulse rate which accompanies extreme sensitivity to the drug. The experiments were carried out 1 to $2 \mathrm{hr}$ after a further oral dose of 80 to $160 \mathrm{mg}$ of propranolol.

Recordings for the male subject are shown in Text-figs. 1a, b, c and d and for the female subject in Text-figs. $2 \mathrm{a}, \mathrm{b}$ and $\mathrm{c}$.

In the male subject, the resting blood pressure was $125 \mathrm{~mm} \mathrm{Hg}$, and in control experiments the pressure rose during coitus to a peak of about 175 $\mathrm{mm} \mathrm{Hg}$ (Text-fig. 1a). One and a half hours after taking $120 \mathrm{mg}$ propranolol orally, the pressure rose to a peak of only $140 \mathrm{~mm} \mathrm{Hg}$ (Text-fig. 1b). This was the most satisfactory result of many experiments which varied the dose level and the time factor. Thus, $1 \mathrm{hr}$ after taking $80 \mathrm{mg}$ propranolol, the peak rise was to $160 \mathrm{~mm} \mathrm{Hg}$ (Text-fig. 1c), while $2 \mathrm{hr}$ after taking $160 \mathrm{mg}$ the peak rise was to $150 \mathrm{~mm} \mathrm{Hg}$ (Text-fig. 1d). The peak rise always corresponded with orgasm. It should be noted that propranolol had a small hypotensive effect on the resting systolic level. The resting pulse rate dropped from $76 / \mathrm{min}$ to $56 / \mathrm{min} 1 \frac{1}{4} \mathrm{hr}$ after taking $120 \mathrm{mg}$ propranolol. Fifteen minutes later, when coitus took place, 
the peak pulse rate was $84 / \mathrm{min}$ compared with the usual pulse rate of about $140 / \mathrm{min}$ at the climax.

In the female subject, the resting systolic pressure was $115 \mathrm{~mm} \mathrm{Hg}$ in control experiments, and the pressure rose during coitus to a peak of about $200 \mathrm{~mm} \mathrm{Hg}$ (Text-fig. 2a). Two hours after taking $160 \mathrm{mg}$ propranolol, the pressure rose to a peak of only $130 \mathrm{~mm} \mathrm{Hg}$ (Text-fig. 2b). This was the most satisfactory result:

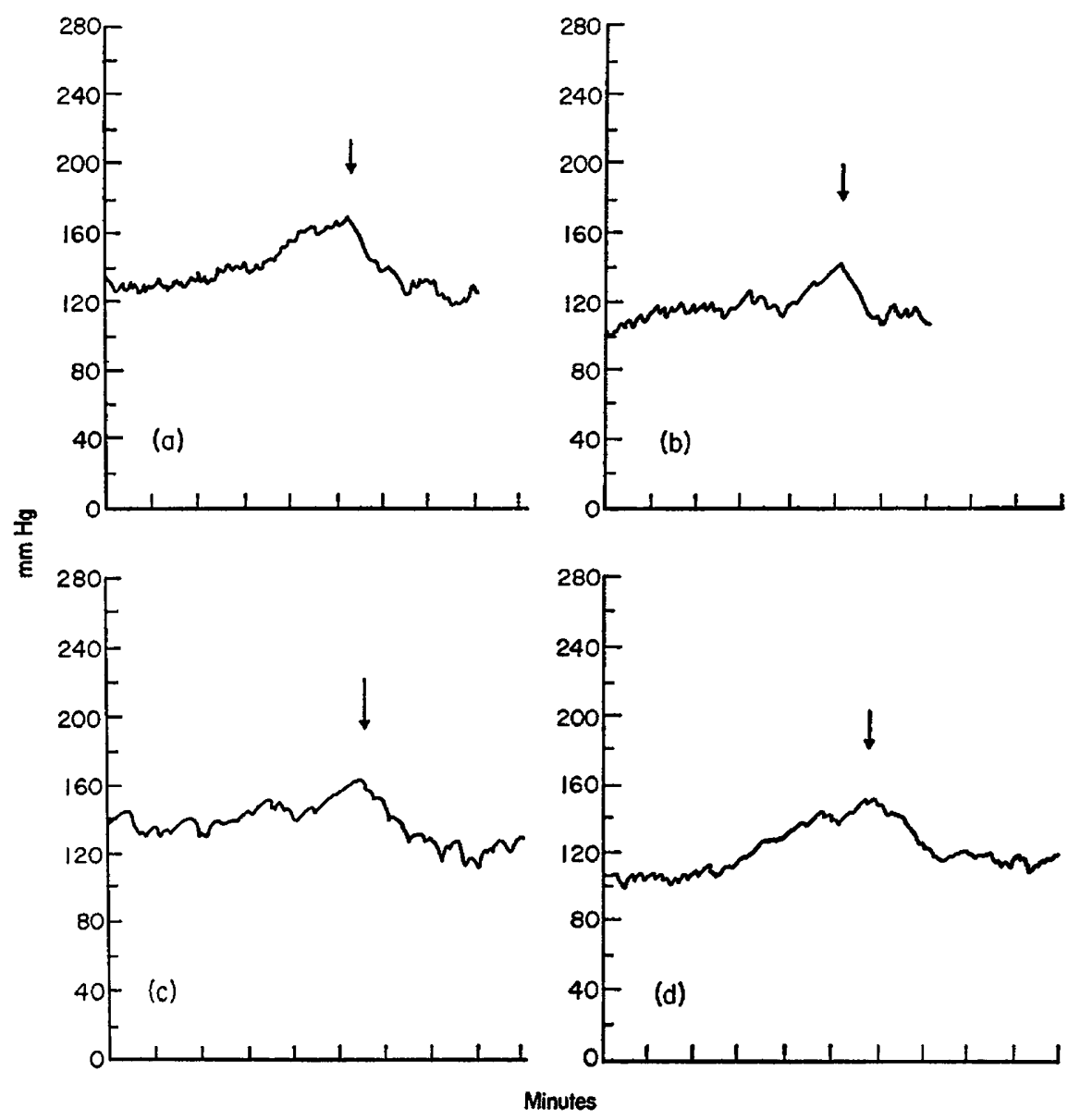

TEXT-FIG. 1. Action of propranolol on the systolic blood pressure of one human male subject during coitus. The arrow indicates orgasm. (a) Control; (b) $1 \frac{1}{2} \mathrm{hr}$ after an oral dose of $120 \mathrm{mg}$; (c) $1 \mathrm{hr}$ after an oral dose of $80 \mathrm{mg}$; (d) $2 \mathrm{hr}$ after an oral dose of $160 \mathrm{mg}$.

thus, for example, $1 \frac{1}{2} \mathrm{hr}$ after taking $100 \mathrm{mg}$, the peak rise was to $160 \mathrm{~mm} \mathrm{Hg}$ (Text-fig. 2c). As with the male experiments, a similar lowering of resting systolic pressure and pulse rate was noted, as well as a reduction of pulse rate at the climax.

Neither subject experienced any difficulty in the attainment of orgasm nor any diminution in its intensity as a result of taking propranolol at any of the dose levels used. The only side-effect was a feeling of coldness in the extremities, particularly the feet, some $2 \mathrm{hr}$ after the dose. 
Previous authors (Klumbies \& Kleinsorge, 1950; Masters \& Johnson, 1966) have discussed the possible dangers of coitus in patients with heart disease. It should be noted that many patients are not advised about sexual activity following recovery from a myocardial infarct, nor is it known to what extent the strain of coitus may be implicated as a precipitating factor, particularly with existing angina. Gazes, Richardson \& Woods (1959) reported an increase in
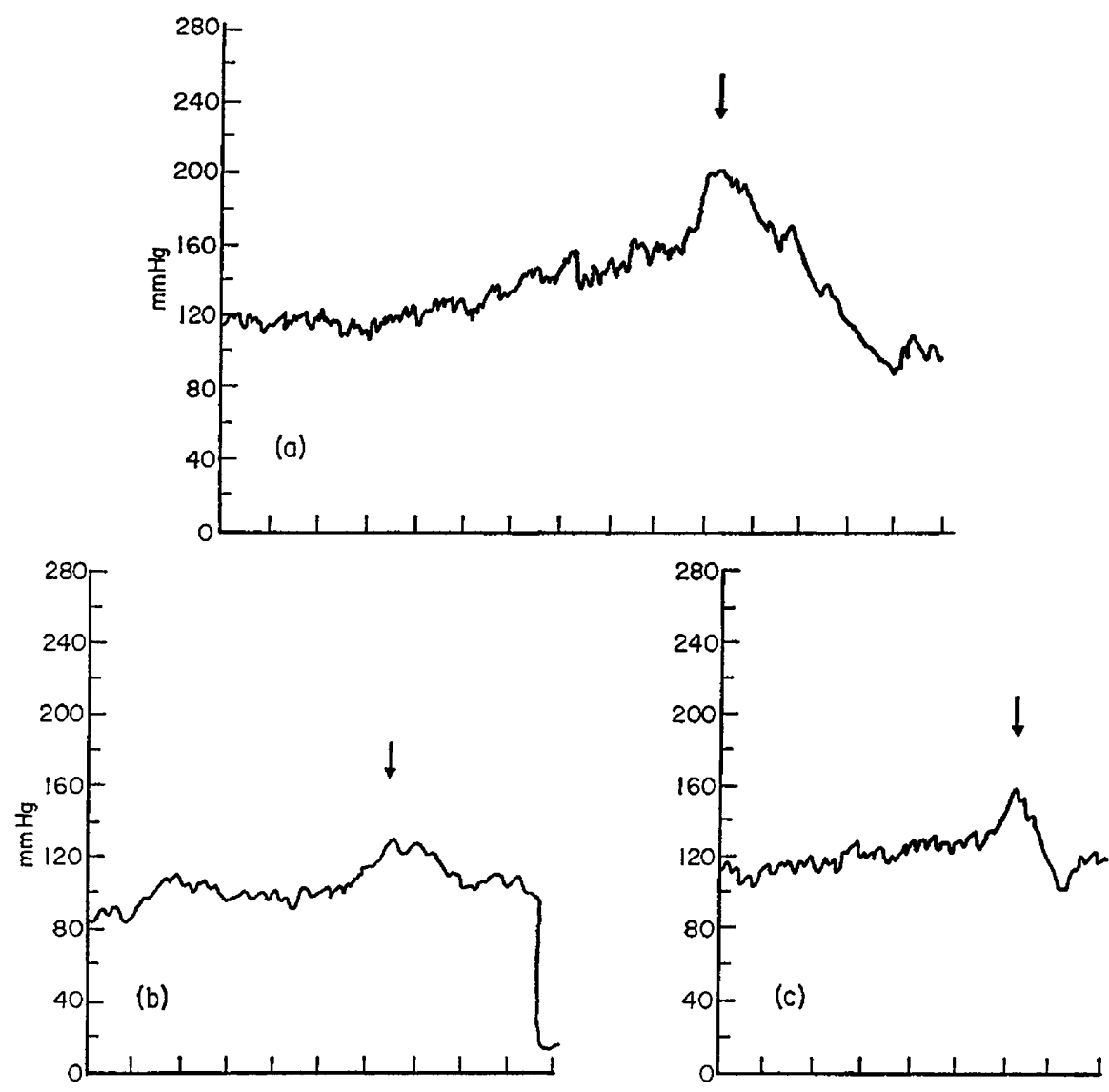

Minutes

TEXT-FIG. 2. Action of propranolol on the systolic blood pressure of one human female subject during coitus. The arrow indicates orgasm. (a) Control; (b) $2 \mathrm{hr}$ after an oral dose of $160 \mathrm{mg}$; (c) $1 \frac{1}{2} \mathrm{hr}$ after an oral dose of $100 \mathrm{mg}$.

plasma catecholamines following exercise in patients with myocardial infarction and angina, compared with normal subjects and patients with non-cardiac pain. In cats, Raab, Van Lith, Lepeschkin \& Herrlich (1962) showed that the catecholamines could induce myocardial hypoxia in the presence of impaired ability of the coronary arteries to dilate. There is no direct evidence of an increase in plasma catecholamines during coitus, but Levi (1965) has shown an increase in the urinary output of adrenaline and noradrenaline during pleasant and unpleasant emotional states. 
For the above reasons, it would seem reasonable to investigate further the effects of a $\beta$-adrenergic receptor blocking agent which not only reduces the pulse rate but also the tachycardia of exercise. In turn, such actions will mean that the pulse rate will be slower after a specific exercise and the force of contraction of the heart will be reduced, with possibly a reduced oxygen requirement.

In considering the cause of the rise of systolic blood pressure during coitus and its subsequent sharp fall to a little below the resting level, the possible release of agents other than the catecholamines has been investigated. The presence of a milk-ejecting agent, probably oxytocin, has been detected in the female, but not in the male, peripheral blood immediately after orgasm (Fox \& Knaggs, 1969). No increase in the blood 5-hydroxytryptamine levels following coitus (unpublished observations), or in the plasma levels of prostaglandins $E_{1}$ and $E_{2}$ (unpublished observations) could be detected. In the light of the findings presented in this paper, it would seem that the rise in blood pressure is mainly due to the increase in pulse rate and cardiac output, probably influenced by muscular tension and by exertion. The exact rôle of the catecholamines remains to be clarified.

While the ability of propranolol to reduce the strain on the cardio-vascular system during coitus may be of benefit to many, its administration may provoke heart failure in certain patients who depend on sympathetic stimulation to maintain their already reduced cardiac output. In addition, by inhibiting the relaxation of smooth muscle, propranolol may produce an attack of bronchospasm in an asthmatic patient. This drug must, therefore, be used selectively and with caution. It is advisable to commence with a small test dose, since some subjects are peculiarly sensitive, and a careful watch on the pulse rate is recommended with increasing dosage. However, propranolol is used widely in the treatment of angina and, latterly, hypertension, and newer $\beta$-adrenergic receptor blocking agents are being developed with a view to greater safety.

\section{REFERENGES}

Fox, C. A. \& Fox, B. (1969) Blood pressure and respiratory patterns during human coitus. F. Reprod. Fert. 19, 405 .

Fox, C. A. \& KNAGgs, G. S. (1969) Milk-ejection activity (oxytocin) in peripheral venous blood in man during lactation and in association with coitus. F. Endocr. 45, 145.

Gazes, P. C., Richardson, J. \& Woods, E. F. (1959) Plasma catecholamine concentrations in myocardial infarction and angina pectoris. Circulation, 19, 657.

Klumbies, G. \& Kleinsorge, H. (1950) Circulatory dangers and prophylaxis during orgasm. Int. $\mathcal{F}$. Sex, 4,61.

LEvi, L. (I965) The urinary output of adrenaline and noradrenaline during pleasant and unpleasant emotional states. Psychosom. Med. 27, 80.

Masters, W. H. \& Johnson, V. E. (1966) Male extragenital reactions. In: Human Sexual Response, pp. 174-176. Churchill, London.

RAAB, W., VAN Lith, P., Lepeschkin, E. \& Herrlich, H. G. (1962) Catecholamine-induced myocardial hypoxia in the presence of impaired coronary dilatability independent of external cardiac work. Am. F. Cardiol. 9, 455. 